\title{
DIMENSIONAMENTO E CONSTRUÇÃO DE UM CONCENTRADOR SOLAR CILÍNDRICO-PARABÓLICO (CSCP) PARA GERAÇÃO DE ENERGIA ELÉTRICA
}

\author{
C. R. de LACERDA, R. F. S. COSTA, A. S. de JESUS, P. M. MORAES e F. L. NAVES \\ Universidade Federal de São João del Rei, Campus Alto Paraopeba, Departamento de \\ Engenharia Química e Estatística \\ E-mail para contato: camilaraqueldelacerda@gmail.com
}

\begin{abstract}
RESUMO - Atualmente, fontes alternativas de energia estão sendo implantadas a fim de reduzir a matriz energética não renovável. Uma boa opção é o uso de radiação solar como fonte de energia térmica e geração de energia mecânica ou elétrica através de concentradores solares. $\mathrm{O}$ concentrador solar cilíndrico-parabólico é constituído de uma superfície refletora cilíndricoparabólica que direciona a radiação solar incidente para a linha focal onde se encontra um tubo absorvedor contendo o fluido que será aquecido. O objetivo desse projeto é construir um concentrador solar do tipo cilíndrico-parabólico para geração de energia elétrica, utilizando água como fluido de trabalho. O concentrador contará com um absorvedor constituído de tubo de cobre com $0,03 \mathrm{~m}$ de diâmetro externo e $1 \mathrm{~m}$ de comprimento, concêntrico a um tubo de vidro borossilicato responsável por manter o isolamento térmico do absorvedor. A superfície refletora cilíndrico-parabólica será recoberta com espelhos de $1 \mathrm{~m}$ de comprimento e $0,002 \mathrm{~m}$ de espessura. Ao final do trabalho, concluiu-se que a potência máxima do tubo absorvedor é de $575,08 \mathrm{~W}$, com uma potência útil de 490,76 W. Isso corresponde a uma eficiência térmica e global de $88,2 \%$ e $67,8 \%$, respectivamente.
\end{abstract}

\section{INTRODUÇÃO}

A evolução tecnológica tornou o ser humano dependente de abastecimento energético para a criação de bens e serviços em prol do seu bem-estar. Por muito tempo, foram utilizadas fontes não renováveis, como petróleo e carvão, que ocasionaram um grande desequilíbrio ambiental, provocando consequências mundiais como os desastres ambientais e uma economia fragilizada pela falta de recursos naturais (Barros, 2007).

No Brasil, a principal fonte de energia é originária das hidrelétricas, que é proveniente da transformação de energia potencial de barragens hídricas em energia mecânica, que é então convertida em energia elétrica. Trata-se de uma fonte energética renovável quando se considera o ciclo da água, mas que gera impactos ambientais como desalojamento de fauna e populacional e a possibilidade de produção de gases estufa com a decomposição da matéria orgânica presente no fundo das barragens (Souza et. al, 2014). Devido à grande extensão territorial, o Brasil possui problemas energéticos particulares, como a distribuição irregular de energia, com áreas de alta densidade populacional e outras muito baixas. Esses fatores, somados à crise energética de 2001, despertaram a busca por outras fontes de energia que fossem renováveis e de fácil implantação por toda extensão territorial, com o intuito de diversificar a matriz energética do país (Pereira, 2015). 
Dentre as alternativas energéticas, a energia solar se destacou por ser uma fonte inesgotável, renovável e que gera pouco impacto ambiental. No Brasil, o uso dessa tecnologia é vantajoso devido às características geográficas e climáticas. Contudo, há poucos estudos para desenvolver materiais e procedimentos que tornem essa fonte viável economicamente e que seja eficiente (Menezes,2014). O objetivo desse trabalho é dimensionar e construir um concentrador solar com a configuração cilíndrico-parabólica que tenha baixo custo e que seja capaz de gerar energia elétrica sem demandar grande espaço físico.

\section{MATERIAIS, MÉTODOS E EQUAÇÕES}

\subsection{Materiais e Métodos}

A estrutura do protótipo do concentrador solar cilíndrico parabólico (CSCP) é composta por sustentação metálica e chapa de aço galvanizado. Os demais elementos do CSCP seguem descritos no Fluxograma da Figura 1.

Figura 1 - Fluxograma do protótipo do concentrador solar cilíndrico-parabólico.

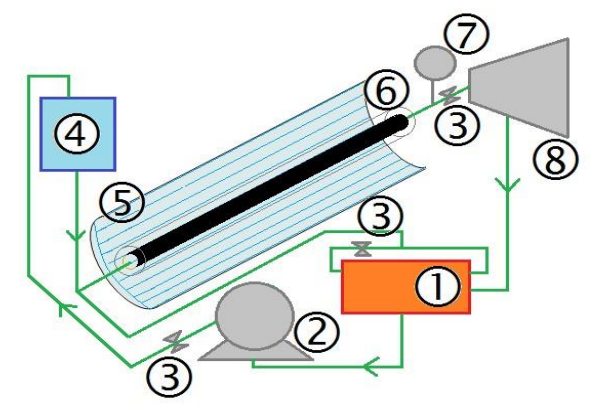

Reservatório de condensado, Bomba de sucção, Válvulas de retenção, Reservatório de fácil acesso, Espelhos planos, Sistema de absorção, Manômetro, Turbina.

As junções dos componentes foram feitas por conexões diretas, conexões em "T", cotovelos, luvas e buchas redutoras, utilizando solda fria, solda quente, abraçadeiras de nylon.

Para garantir a radiação concentrada no foco todo o tempo, utilizou-se o sistema manual de deslocamento do concentrador em direção aos raios solares, pois é necessário garantir o aproveitamento dos raios solares diretos.

O protótipo montado pelo grupo está representado na imagem da Figura 2.

Figura 2 - Protótipo final montado pelo grupo.

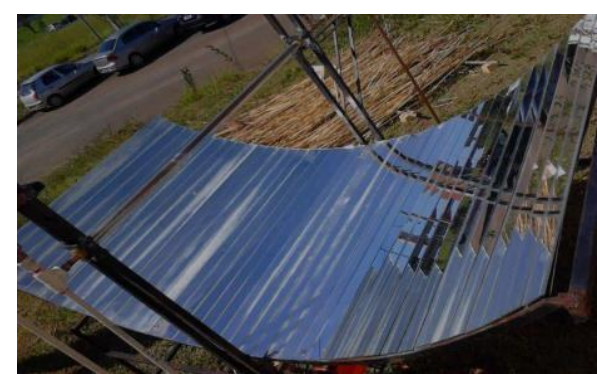

\subsection{Equações}




\section{Congresso Brasileiro de Engenharia Química \\ em Iniciação Científica \\ UFSCar - São Carlos - SP \\ 16 a 19 de Julho de 2017}

De acordo com Filho (2008), a conversão da radiação solar direta em energia térmica passa pelos estágios óptico, com a captação e reflexão da radiação solar; e térmico, com a transferência de calor para o fluido de trabalho. A água foi o fluido de trabalho escolhido. A geração de vapor, na etapa de absorção, permite acionar uma turbina promovendo a conversão de energia térmica em elétrica. As variáveis existentes nesse processo são: Id - Radiação solar direta coletada pelo sistema de captação $\left(\mathrm{W} / \mathrm{m}^{2}\right) ; \mathrm{P}_{\mathrm{abs}}$ - Potência máxima que chega ao tubo absorvedor (W); $\mathrm{P}_{\text {conv }}$ - Potência perdida por convecção $(\mathrm{W})$; $\mathrm{P}_{\mathrm{rad}}$ - Potência perdida por radiação para o ambiente $(\mathrm{W})$; Ac - Área total da superfície de captação $\left(\mathrm{m}^{2}\right)$; As - Área sombreada pelo tubo absorvedor $\left(\mathrm{m}^{2}\right)$; Ai - Área do absorvedor iluminada pela radiação refletida $\left(\mathrm{m}^{2}\right)$.

A área útil do refletor $(\mathrm{Au})$ não considera a área sombreada pelo tubo absorvedor (As), ou seja, a área útil é dada pela diferença entre a área de abertura do concentrador e a área sombreada, o que é mostrado pela Equação 1.

$$
A u=A c-A s
$$

A área iluminada pode ser calculada pela Equação 2.

$$
A_{\mathrm{i}}=\pi D L
$$

A potência absorvida máxima é descrita pela Equação 3.

$$
P_{a b s}=I d \cdot \rho \cdot A u, \alpha \cdot k
$$

Sendo: Pabs - Potência absorvida (W); Id - Radiação solar incidente $\left(\mathrm{W} / \mathrm{m}^{2}\right) ; \rho$ - Refletividade do concentrador (\%); k - Fração de radiação refletida que chega ao absorvedor (\%); $\alpha$ Absortividade do tubo coletor $(\%)$.

A potência perdida durante o processo de aquecimento pode ser dada pela Equação 4.

$$
P L=P_{\text {conv }}+P_{\text {rad }}=h A\left(T_{a b s}-T_{\infty}\right)+\varepsilon \sigma A\left(T_{a b s}^{4}-T_{\text {viz }}^{4}\right)
$$

Sendo: PL - Potência perdida (W); h - Coeficiente de película $\left(\mathrm{W} / \mathrm{m}^{2} \mathrm{~K}\right)$; A - Área do tubo absorvedor $\left(\mathrm{m}^{2}\right) ; \mathrm{T}_{\mathrm{abs}}$ - Temperatura do tubo absorvedor $(\mathrm{K}) ; T_{\infty}=T_{\text {viz }}$ - Temperatura no estado estacionário (ambiente, K); ${ }^{\varepsilon}$ - Emissividade do tubo absorvedor; ${ }^{\sigma}$ - Constante de Stefan-Boltzman $\left(5,67 \times 10^{-8} \mathrm{~W} / \mathrm{m}^{2} \mathrm{~K}^{4}\right)$.

O coeficiente de película (h) pode ser obtido a partir de uma relação empírica de Nusselt, que envolve a condutividade térmica do ar e o diâmetro do tubo absorvedor. O número de Nusselt está relacionado ainda com dois outros adimensionais, o número de Reynolds $(\mathrm{Re})$ e o número de Prandtl (Pr), por uma relação também empírica.

A potência útil foi obtida pela Equação 5 .

$P_{u}=P_{a b s}-P L$

A eficiência óptica está associada à Equação 6.

$\mu=\rho k \alpha$

A eficiência térmica é o percentual de energia útil no tubo absorvedor que se converte em calor e está representada pela Equação 7. 


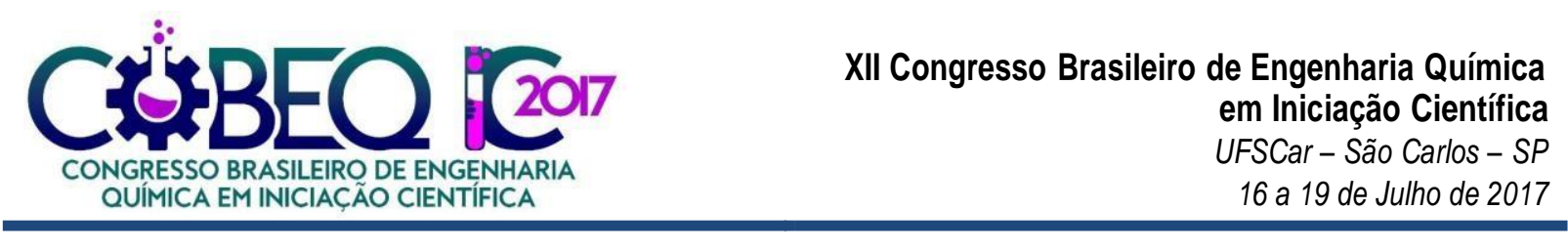

$$
\mu_{\mathrm{t}}=\frac{\mathrm{pu}}{\mathrm{Id} \cdot \mathrm{Au}_{\mu_{\mathrm{o}}}}
$$

Desse modo, a eficiência global é dada pela Equação 8.

$$
\mu=\mu_{0} \times \mu_{t}
$$

Pode-se ainda definir um parâmetro que está relacionado diretamente com o aquecimento do tubo absorvedor, o fator de concentração (FC), segundo a Equação 9.

$$
\mathrm{FC}=\frac{\mathrm{A}_{\mathrm{u}}}{\mathrm{A}_{\mathrm{i}}}
$$

\section{RESULTADOS E DISCUSSÃO}

A radiação direta solar foi determinada por um radiômetro portátil e teve a média de $490 \mathrm{~W} / \mathrm{m}^{2}$, na cidade de Ouro Branco - MG, local onde está o Campus Alto Paraopeba da Universidade Federal de São João del Rei. A área de abertura do concentrador é de 1,5 $\mathrm{m}^{2}$, a área sombreada é de $0,047 \mathrm{~m}^{2}$. A refletividade do vidro borossilicato será estipulada em $95 \%$, $(\rho=0,95)$. A radiação refletida que chega ao absorvedor é de $90 \%,(\mathrm{k}=0,90)$. A absortividade do cobre está entre 90 a 96\% e será utilizado o valor de 93\%, $(\alpha=0,93)$ (Filho, 2008). Sendo assim, os resultados obtidos pela resolução das Equações 1 - 9 estão dispostos na Tabela 1.

Tabela 1 - Resultados dos parâmetros obtidos pelas Equações 1 - 9

\begin{tabular}{|l|l|l|l|l|l|l|l|c|}
\hline $\mathrm{A}_{\mathrm{u}}\left(\mathrm{m}^{2}\right)$ & $\mathrm{A}_{\mathrm{i}}\left(\mathrm{m}^{2}\right)$ & $\mathrm{P}_{\mathrm{abs}}(\mathrm{W})$ & $\mathrm{PL}(\mathrm{W})$ & $\mathrm{P}_{\mathrm{u}}(\mathrm{W})$ & $\mu_{0}(\%)$ & $\mu_{\mathrm{t}}(\%)$ & $\mu(\%)$ & $\mathrm{FC}$ \\
\hline 1,453 & 0,0942 & 575,08 & 84,32 & 490,7 & 76,9 & 88,2 & 67,8 & 15,67 \\
\hline
\end{tabular}

Os resultados encontrados a partir da resolução das equações mostraram que o concentrador solar construído possui grande viabilidade econômica, visto que o custo de produção foi baixo e as eficiências resultantes foram consideravelmente altas. Levando em consideração que o Brasil é um país que possui uma elevada taxa de irradiação solar, esse projeto poderia ser de grande valia, principalmente em locais com maior dificuldade de transmissão de energia elétrica e elevada taxa de irradiação, como por exemplo, em áreas de sertão ou mesmo desérticas. Pode-se pensar também nos casos em que a tarifa de energia elétrica é bastante elevada e isso torna o uso da energia solar mais competitivo.

A título de comparação, o rendimento global de uma usina a vapor é de 40-46\% e de uma usina a gás é de 35-40\%, enquanto o rendimento global do concentrador solar cilíndricoparabólico é de 67,8\% (França, 2001).

O Brasil progrediu em sua capacidade solar térmica e em 2013 ocupava a quinta posição no mercado de aquecimento solar. O país tem conseguido se manter em posições relevantes nesse mercado, portanto se forem criadas e utilizadas normas regulamentadoras e mecanismos de incentivos mais eficazes, com seu grande potencial, a tendência é que o mercado solar evolua cada vez mais (Cabral et al., 2013).

\subsection{Testes de Geração de Vapor}

No dia 05 de fevereiro de 2014, um dia ensolarado, com previsão de tempo marcando as temperaturas mínimas e máximas de $19^{\circ} \mathrm{C}$ e $28^{\circ} \mathrm{C}$, respectivamente, foram feitos testes para confirmar a geração de vapor. Com o auxílio de um cronômetro foram anotados os tempos proporcionais ao aumento da pressão interna, aferida pelo manômetro. Os dados obtidos estão 
expostos na Figura 3, que mostra o perfil de geração de vapor pelo concentrador solar cilíndricoparabólico montado.

Figura 3 - Produção de vapor vs tempo.

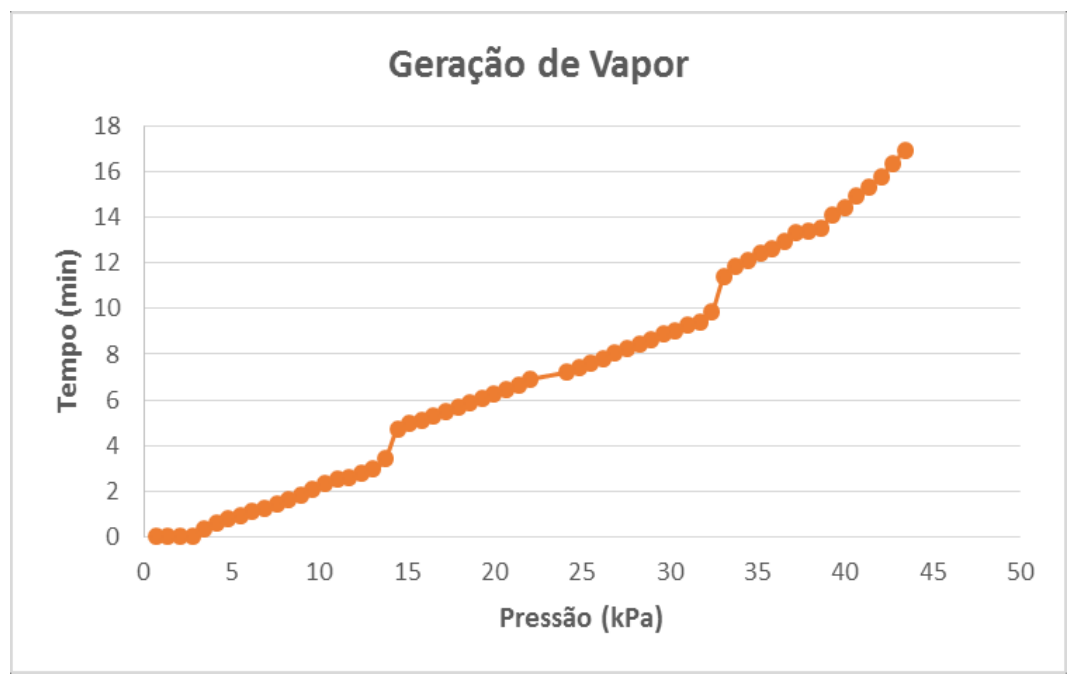

Pode-se perceber duas inclinações no gráfico, quando a pressão atinge 13,8 e 31,8 kPa. Tal fato pode ser justificado pela aparição de nuvens entre o sol e o concentrador, o que fez diminuir a incidência de raios solares no concentrador. Analisando-se a curva obtida, pode-se observar uma linearidade em relação ao aumento de pressão e tempo, o que pode ser justificado pela absorção gradativa dos raios solares, atingindo o máximo e comprovando que o nível de absorção atingiu o seu máximo.

\section{CONCLUSÃO}

O presente trabalho apostou no concentrador solar cilíndrico-parabólico para geração de energia elétrica devido ao fato de que esses concentradores são a mais madura tecnologia solar de geração de calor e permitem o aquecimento de fluidos a temperaturas elevadas.

A construção do concentrador solar se mostrou relativamente simples, podendo ser utilizada como uma fonte de energia adicional à energia elétrica, visto que o mesmo necessita de dias ensolarados, presentes em algumas estações do ano, para apresentar boa absorção da radiação solar e consequente produção de vapor implicando na geração de energia elétrica.

Com o clima propício da região e o alto índice de radiação, a iniciativa se mostrou interessante. Além do projeto ser de baixo custo, tem-se a facilidade de locomoção e instalação para o local desejado e simples monitoramento dos resultados.

O concentrador solar construído mostrou-se termicamente viável produzindo vapor, além de apresentar bons resultados de eficiência térmica, óptica e global quando comparado a outras formas de geração de energia elétrica, como por exemplo a termelétrica.

\section{REFERÊNCIAS}

BARROS, E. V. de. A matriz energética mundial e competitiva das nações: base de uma nova geopolítica. Universidade Federal Fluminense, Departamento de Eng. de Produção. ENGEVISTA, v. 9, n. 1, p. 47-56, 2007.

CABRAL, I. de S.; TORRES, A. C.; SENNA, P. R. Energia solar - análise comparativa entre Brasil e Alemanha. IV Congresso Brasileiro de Gestão Ambiental. Salvador, 2013. 
FILHO, J. R.S. Projeto, construção e levantamento de desempenho de um concentrador solar cilíndrico-parabólico com mecanismo automático de rastreamento solar. 91 folhas. Dissertação UFRN. Natal, 2008.

FRANÇA, A. L. M. Geração de energia elétrica. Cap.3. 2001.

MENEZES, S. D. S. Energias renováveis utilizadas pelo mundo. Universidade Estadual da Paraíba. Departamento de Engenharia Sanitária e Ambiental. Campina Grande, 2014.

PEREIRA, B. P. C. Análise de eficiência energética em rede inteligente de energia elétrica. Universidade Federal de Santa Maria, Especialização Eficiência Energética aplicada aos Processos Produtivos. Camargo, 2015.

SOUZA, V. O.; AMARAL, R. C. O do; LACERDA, C. C. de O.; SILVA, M. E. da; SOUZA, S. M. A. de. .Universidade Estadual da Paraíba. Revista Gestão Industrial. ISSN 18080448 / v. 10, n. 1, p. 22-36, 2014. 